\title{
Artful Liars: Malingering on the Draw-A-Person Task
}

\author{
Dennis P. Carmody ${ }^{1, *}$ and Angela M. Crossman ${ }^{2}$
}

\author{
${ }^{1}$ Institute for the Study of Child Development, Robert Wood Johnson Medical School - University of Medicine and \\ Dentistry of New Jersey, New Brunswick, NJ, U.S.A.; ${ }^{2}$ John Jay College of Criminal Justice, City University of New \\ York, New York, NY, U.S.A
}

\begin{abstract}
Malingering is a form of deception in which one fakes illness to earn (positive or negative) reinforcement. The purpose of the current research was to explore the ability of naïve participants to malinger distress on a clinical, projective measure (Draw-A-Person; DAP). In two experiments, individuals first drew figures of a man, woman, and self. Then, they imagined they were in a motor vehicle accident and drew the figures again as if they were falsely claiming distress from the accident. In Experiment 1, 65 undergraduates participated and in Experiment 2, 70 undergraduates and 40 high school students participated. The drawings were objectively scored using a standardized protocol and 'honest' and 'malingered' drawings were compared. In both Experiments, participants successfully malingered distress and did so by drawing more "primitively", earning lower cognitive ability scores on their malingered drawings. Hence, objectively-scored DAP tasks are vulnerable to deliberate distortion by naïve individuals, though malingering detection may be possible in the future via cognitive skill scores. However, reliance on DAP tasks for diagnostic or forensic purposes currently seems questionable.
\end{abstract}

Keywords: Deception, posttraumatic stress disorder (PTSD), trauma, cognitive ability, projective tests.

\section{INTRODUCTION}

Most individuals are well practiced in deliberate distortion. In fact, whether it is telling little white lies or whoppers, most children are competent liars by the time they reach adolescence (Faust, Hart, \& Guilmette, 1988; Quinn, 1988; Talwar \& Lee, 2002a, b; Wilson, Smith, \& Ross, 2003). They can be very successful when lying to their parents, for example, with only $5 \%$ of the adolescents in one study reporting that they were often caught (Knox, Zusman, McGinty, \& Gescheidler, 2001). They successfully lie to trained professionals, as well. Faust, Hart, Guilmette and Arkes (1988) found that three adolescents (ages 15-17 years) with minimal instruction were able to fake brain damage on neuropsychological assessments, such that none of the 64 neuropsychologists who participated detected the deception. These findings were replicated with three 9- to 12-year-old children (Faust, Hart, \& Guilmette, 1988). Hence, skill in deception of various sorts is acquired before adolescence.

Despite the frequency of lying throughout normal development (DePaulo et al., 2003; Knox et al., 2001; Wilson et al., 2003), it is not clear how adolescents and even adults understand and commit deception in different contexts, particularly those that might be forensically relevant (Carmody $\&$ Crossman, 2005). Hence, the first objective of the present research was to explore deception in a relatively novel context, that of feigning a serious psychological impairment (i.e., emotional disturbance). The context was an imagined motor vehicle accident, after which subjects were to claim

*Address correspondence to this author at the Institute for the Study of Child Development, Robert Wood Johnson Medical School, University of Medicine and Dentistry of New Jersey, 97 Paterson Street, New Brunswick, New Jersey 08903; USA; Tel: (732) 235-7699; Fax: (732) 235-6189;

E-mail: carmoddp@umdnj.edu emotional distress to gain a large sum of money. Such cases can involve forensic psychologists as experts, raising the controversial issue of credibility assessment and how it can be accurately accomplished. Yet, the issue is relevant in additional contexts, as well. That is, in some treatment-oriented settings, individuals may over-report or exaggerate symptoms of poor cognitive or emotional functioning (Kropp \& Rogers, 1992; McCann, 1998). As a consequence, there is a growing need to apply reliable, valid, and practical methods for assessing deception among clients and patients, some of whom are adolescents and young adults. Hence, the second objective of the current research was to explore the vulnerability of one projective test, the Draw-A-Person test, to participants' feigning of emotional disturbance.

\section{Human Figure Drawing}

Human figure drawing is a performance-based clinical procedure in which an individual is asked to draw human figures, and these drawings are then analyzed. Although the procedure has gone through different permutations with different names, Draw-A-Person (DAP) task is a generic term for the general procedure, and is the term that will be used here. As with other projective and performance-based evaluation tools, the validity of DAP tasks is debated and attempts to validate the task have led to the evolution of various procedures and scoring systems for DAP tests, some of which are more objective than others (e.g., see Handler, 1984; Sims, Dana, \& Bolton, 1983). Among these systems, it appears that procedures emphasizing global quantitative drawing scores (rather than seeking specific 'signs' of pathology, such as oversized eyes) are the least problematic and most promising, in terms of validity (Lilienfeld, Wood, \& Garb, 2000; Riethmiller \& Handler, 1997). 
Clinically speaking, human figure drawing is considered to be a relatively non-threatening, nonverbal method for beginning counseling situations (Lev-Wiesel \& Hershkovitz, 2000; Riethmiller \& Handler, 1997) and, as a consequence, has been used in a variety of settings including prisons, schools, counseling centers and in several cultures. DAP tests are used routinely in educational, psychological, and forensic settings with adults and children with learning, behavioral, and developmental problems (Camara, Nathan, \& Puente, 2000; Dykens, 1996). In fact, due to the flexibility of the task, DAP tests have been used in assessments of emotional disturbance, gender identity, cognitive delay, trauma, sexual abuse, and even violently aggressive behavior in prisoners, among others (Aldridge et al., 2004; Lev-Wiesel \& Hershkovitz, 2000; Ochoa, Riccio, Jimenez, de Alba \& Sines, 2005; Tharinger \& Stark, 1990). Moreover, while human figure drawing is frequently used in clinical settings for assessment (e.g., custody evaluations, Ackerman \& Schoendorf, 1992; Bricklin, 1984), it also has been used in therapy with children (Burgess \& Hartman, 1993; Peterson, Hardin, \& Nitsch, 1995; Wilson \& Ratekin, 1990).

\section{Malingering PTSD on a Projective Test}

Serious concerns have been raised about the validity and reliability of the DAP method (Lilienfeld et al., 2000; Smith \& Dumont, 1995). Critiques include insufficient training of clinicians using the method (Smith \& Dumont, 1995), reliance on unsubstantiated 'signs' in drawings as indices of pathology, and redundancy with other, more valid and meaningful measures, such as IQ measures (Lally, 2001; Lilienfeld et al., 2000). Moreover, additional research indicates that some children can be vulnerable to suggestion when their drawings are used to probe memory (Bruck, Melnyk, \& Ceci, 2000; Strange, Garry, \& Sutherland, 2003).

Yet, beyond questions of task validity and patient vulnerability is the issue of deliberate distortion on the task. It is possible for individuals to deliberately misrepresent themselves in assessment settings, perhaps for their own gain. Specifically, malingering occurs when one fakes or exaggerates an illness or disability to gain a reward or avoid a negative outcome. It has been suggested that some forensic settings (e.g., litigation) encourage symptom exaggeration, at a minimum (Blanchard \& Hickling, 1997). Malingering is thought to be common among personal injury litigants seeking compensation, with estimates of the incidence of malingering post-injury psychological symptoms ranging from 1 to over 50\% (Resnick, 1997). Hence, standardized instruments are increasingly being used in litigation contexts, perhaps due to their objectivity and the fact that many include empirically tested scales for detecting biased response patterns (Berry, 1995; Guriel et al., 2004).

Given the widespread use of DAP testing, one might ask how vulnerable such tests are to malingering, even when a standardized scoring system is used, as pathological responding on projective testing has been found to be 'fakable' (Rogers, 2008; Schretlen, 1997). In particular, in forensic cases where PTSD is at issue, psychological opinion might be requested in court. To the extent that such opinion rests on projective testing, it is problematic. At present, the most commonly used methods for interpreting human figure drawings fall short of meeting the Daubert standard for admissi- bility in court (Lally, 2001). Moreover, human figure drawing methods do not meet most of Heilbrun's (1992) guidelines for use in forensic assessment, although reliance on overall rating scales appears to minimally meet these standards (Lally, 2001). An objective rating procedure (i.e., the DAP: SPED, see below) and its overall rating scale at least partially meet a number of guidelines and criteria, with the potential to meet more of the guidelines, if additional research is conducted (Lally, 2001; see also Lilienfeld et al., 2000).

\section{Objective Scoring}

Clinical use of DAP procedures is common, although it is not clear that such use is warranted or appropriate (Dykens, 1996; Matto, 2002; Smith \& Dumont, 1995). Historic reliance on specific 'signs' in the interpretation of drawings is not generally supported by the empirical literature (Lally, 2001; Lilienfeld et al., 2000). Recent efforts to standardize evaluation of the projective DAP tasks have resulted in objective scoring systems by Naglieri and colleagues (Naglieri, 1988; Naglieri, McNeish, \& Bardos, 1991), which provide cognitive and emotional disturbance scores from drawings. Aggregating scores across components within the scoring systems arguably provides the greatest advantage to using the objective scoring (Riethmiller \& Handler, 1997).

The Naglieri scoring systems have been used to evaluate the cognitive scores (Naglieri, 1988) and emotional disturbance scores (Naglieri et al., 1991) of a group of adolescents and adults with mental retardation. Researchers found modest correlations between DAP cognitive scores and vocabulary $(r=.34)$ and matrices $(r=.41)$ scores on the Kaufman Brief Intelligence Test, and an association was found between emotional disturbance scores and social adaptation from the Vineland ( $r=.36$; Dykens, 1996).

Questions remain, however, as to the extent to which these standardized scoring systems are vulnerable to deliberate distortion by adolescents (e.g., Lilienfeld et al., 2000). Of primary concern is the vulnerability of the objectively scored Draw-A-Person task to malingering, which has yet to be tested. Hence, the current experiments examined whether Naglieri's objective scoring systems might be of value in the detection of intentional feigning of emotional distress through human figure drawings.

\section{Malingering and Deception Detection}

As noted above, deception is not a foreign practice to individuals. In fact, many are likely to have experience with malingering as well since, by definition, malingering can be as simple as a child claiming illness to avoid taking a test at school. It can also be as complicated as an alleged criminal claiming mental illness to avoid a criminal conviction. However, there currently exists little empirical research on malingering in forensic contexts among adolescents and young adults, particularly when projective tests are used (Rogers, Hinds, \& Sewell, 1996), with most models of adolescent malingering based on clinical reports (McCann, 1998). Moreover, although one might argue that projective tests are difficult to malinger, due to a lack of transparency, it is not clear whether younger individuals are capable of doing so. Hence, the current studies provide novel data on the impact on the quantitative global scores when naïve participants attempt to dissimulate on a projective measure. 
Clinical settings do not appear to be immune to attempts at intentional feigning, and researchers' best estimate for the prevalence rate of malingering psychopathology is approximately $15.7 \%$, among adolescents in forensic practice (Rogers et al., 1996). Moreover, most individuals are likely to be aware of the potential for material gain following traumatic injury. Indeed, the DSM recognizes that, by definition, some disorders practically invite individuals to deliberately misrepresent themselves in assessment settings for their own gain, particularly post-traumatic disorders (American Psychiatric Association, 1994). Lawsuits in such cases (e.g., suits alleging trauma following a motor vehicle accident) arguably often entail the exaggeration of cognitive impairments or emotional distress in the pursuit of financial compensation, leading to numerous pejorative terms for posttraumatic symptomatology (e.g., compensationitis; etc., Resnick, 1997).

The current research examined the effectiveness of adolescents and young adults to malinger when asked to feign such post-traumatic symptoms following a motor vehicle accident (MVA). These individuals are of particular interest, as they tend to be the group most frequently involved in MVAs (National Highway Traffic Safety Administration, 2001). Given appropriate circumstances, such individuals might experience the temptation (or parental or financial pressure) to feign post-traumatic symptoms in a forensic assessment. Previous findings indicate that young adults are capable of dissimulating trauma following an imagined MVA on a standardized measure - the Trauma Symptom Inventory (Carmody \& Crossman, 2005). However, on average, their deception tended to be detectable, though not completely so. If an examiner instead introduced a DAP task to facilitate a patient's recollection of a traumatic memory, it is not clear whether malingering would be more or less detectable on this projective measure. Hence, the means by which participants attempt to malinger emotional distress on a projective DAP task were explored.

\section{The Current Research}

Overall, there were two primary goals of the present research. The first was to contribute to the sparse empirical literature on deception and malingering in psychological testing, particularly among adolescents and young adults. Specifically, the goal was to determine whether these young participants would be capable of fabricating emotional distress in their human figure drawings and, if so, in what way. It was anticipated that participants would be able to feign emotional distress on human figure drawings. The second goal was to examine the vulnerability of the projective DAP task to malingering and explore whether the DAP objective scoring systems might have the potential to detect malingering. Two experiments were conducted with college and high school students to explore these issues.

\section{EXPERIMENT 1}

\section{Method}

\section{Participants}

The participants in this study were 62 undergraduate college students from introductory psychology classes volunteering in exchange for course credit. The sample was 53\% female $(n=32)$, with an age range of $18-22$ years $(M=18.92$ years, $S D=1.26$ ) and was widely representative in terms of SES (ranging from low to high SES) and race/ethnicity. Ethnic distribution of the participants was 16\% African American, 10\% Asian American, 45\% Caucasian, and 29\% Latin American. One female participant was excluded due to failure to draw two figures. The study was approved by the Institutional Review Board at the undergraduate college where data were collected.

\section{Procedure}

Participants signed informed consent, provided demographic information (i.e., age, gender, and ethnic identity), and then were asked to draw figures. In the honest condition, standard instructions were followed. That is, participants drew the three figures: man, woman, and self, for a maximum time of five minutes per figure. Participants were instructed to draw complete figures and to draw the best figures possible. Next, a scenario was read to participants to begin the malingering phase of the study:

Suppose you were involved in a motor vehicle accident. Your friends inform you that you may gain a large sum of money if you claim psychological distress. You begin to claim that you have many disturbing symptoms. When you go for an evaluation, the interviewer asks you to draw human figures. Draw the figures as if you are claiming distress as a result of the motor vehicle accident.

After hearing the scenario, participants were asked to draw the figures again (i.e., man, woman, and self) as if they were claiming distress due to the accident. Overall, each individual drew a total of 6 figures. Use of the same participants in both conditions allowed for control of basic artistic abilities and of intelligence between participants (Handler, 1984; Sims et al., 1983). Testing was conducted in small groups of 2-5 participants, and all responses were anonymous.

\section{Rater Training and General Scoring}

Prior to scoring the study drawings, the judge completed the training sections of the Examiner's Manual, which required learning the scoring system, scoring practice drawings, and then completing a competency examination of a new set of drawings that required a minimum competency of $90 \%$ correct. All 372 figures were scored for the 64 items on the cognitive assessment and the 55 items on the emotional disturbance assessment, as described below. Scoring was completed by a judge who was not blind to the conditions. Although this may be of concern with a subjective scoring system, there is evidence that knowledge of the status of patients might not affect the objective scoring system of the DAP:SPED (Bruening, Wagner, \& Johnson, 1997).

\section{Scoring - Cognitive Scores}

Drawings were scored using Naglieri's (1988) Quantitative Scoring System (QSS), which arguably serves as a valid and reliable measure of nonverbal cognitive ability (Williams, Fall, Eaves, \& Woods-Groves, 2006). The three major components of the QSS scoring system are criteria, categories, and items. The 14 criteria include body parts and placement of the parts in relation to others. Four categories for all criteria are presence, detail, proportion, and a bonus. A total of 64 items are scored for completion and the sum of 
the 64 items yields an overall score for each figure drawn. Using the test manual, these scores were converted to standard scores, according to chronological age, for further analyses. Higher scores on the QSS indicate higher cognitive abilities.

Naglieri's (1988) norms for the QSS were based on a geographically and ethnically representative standardization sample of 5-17-year-olds. Coefficient alphas for the 14 criteria on all three drawings ranged from .83 to .89 (for one-year age groups). Reliability coefficients for the individual drawings of man, woman, and self were lower, ranging from .56 to .78 , with a median coefficient of .80 . Interrater reliability for items was .91 to .94 and for overall scores, was .92 to .95. Concurrent validity of the DAP:QSS with cognitive ability was assessed using the Matrix Analogies Test - Short Form (MAT-SF). Correlations were .29 to .31 for younger children (grades $\mathrm{K}$ to 3 ) and .19 to .27 for older children (grades 4 to 12).

\section{Scoring - Emotional Disturbance Scores}

Drawings also were scored using the Screening Procedure for Emotional Disturbance (SPED; Naglieri et al., 1991). The two major components of the scoring system for the SPED are figure dimensions and figure content. Figure dimensions include figure size and placement on the page (9 scores) and figure content refers to details of the drawings (46 details scored as present or absent). The sum of the 55 ratings yields an overall score for each drawing. The raw scores for the three drawings by each participant were summed to yield a total score. Using the test manual, these scores were converted to standard scores, according to chronological age and gender, for further analyses. Higher scores on the SPED indicate higher levels of emotional disturbance.

Naglieri et al.'s (1991) norms for the SPED were based on a geographically and ethnically representative standardization sample of 5-17-year-olds. Coefficient alphas for standard scores ranged from .67 to .78 (for gender and age groups). Test-retest correlation of standard scores was .67, interrater reliability was .84 , and intrarater reliability was .83. In this study, as well as in Experiment 2, aggregate scores for both the DAP:QSS and DAP:SPED were used, as they tend to represent the strongest advantage offered by the objective scoring system (Riethmiller \& Handler, 1997).

\section{Results}

A preliminary multivariate analysis of variance (MANOVA) was used to determine if there were differences in scores for the figures of man, woman, and self. There were no significant differences among the figure drawings in the emotional disturbance or cognitive scores in the honest and malinger conditions, Wilks' Lambda $=0.99, F(4,736)=$ $.15, n s$, eta squared $=.001$. Therefore, further analyses used the total scores, composed of the combined scores of man, woman, and self, for the emotional disturbance and cognitive scoring systems.

Table 1 presents the means of the total cognitive and total emotional scores for the honest and malinger instructional conditions. A repeated measures analysis of variance (ANOVA) was performed on the cognitive scores, with condition (honest vs. malinger) as a within-subjects variable and gender as a between-subjects factor. As shown in Table 1, there was a significant main effect for condition, which reflected higher scores in the honest condition than in the malinger condition. A repeated measures ANOVA on the emotional disturbance scores, with condition (honest vs. malinger) as a within-subjects variable and gender as a betweensubjects factor, revealed an effect for condition, with higher scores in the malinger condition than in the honest condition.

As shown in Table 1, there were no gender differences in either total cognitive scores or total emotional disturbance scores and no significant interactions between condition and gender.

\section{Discussion}

Under instructions to malinger distress, students drew figures that led to higher scores of emotional disturbance and lower scores of cognitive ability. This suggested that perhaps the participants were attempting to fake distress, in part, by "dumbing down" their drawings. However, in considering possible alternatives, it became clear that some of the participants had rushed their drawings, spending less than the full 5 minutes in drawing the best figures possible. This raised the possibility that the findings were related to the motivational level of the participants, rather than to the malingering instructions. Hence, a replication of the study was conducted to determine whether increased attention to the task would alter performance. In addition, a younger sample of participants was included to determine if the findings also occur among adolescents.

\section{EXPERIMENT 2}

\section{Method \\ Participants}

Two samples of individuals were included in this study. Sample 1 consisted of 66 undergraduate college students from introductory psychology classes volunteering in exchange for course credit. The sample was $58 \%$ female $(n=$ $38)$, with an age range of $18-22$ years $(M=19.23$ years; $S D$ $=1.19$ ), and was widely representative in terms of SES (ranging from low to high SES) and race/ethnicity. Participants in this sample were 30\% African American, 10\% Asian American, 21\% Caucasian, 33\% Latin American, and $6 \%$ mixed ethnicity. One female participant was excluded due to failure to draw one figure. The study was approved by the Institutional Review Board at the undergraduate college at which data were collected.

Sample 2 consisted of 40 high school students. The sample was $62 \%$ female $(n=25)$, with an age range of $14-17$ years $(M=16.00$ years; $S D=0.78)$. Participants in this sample were 18\% African American, 5\% Asian American, 28\% Caucasian, 35\% Latin American, and 14\% mixed ethnicity. Students were recruited based on their voluntary responses to a letter offering the students an opportunity to participate in a psychological study. There were no financial rewards and the data were collected during a homeroom period.

\section{Procedure}

The procedure and figure scoring were identical to those used in Experiment 1, with a few minor exceptions. First, in order for the undergraduate participants to receive credit for 
Table 1. Draw-A-Person Scores by Instructions and Gender, Experiment 1

\begin{tabular}{|c|c|c|c|c|c|}
\hline \multirow[t]{2}{*}{ Scores } & \multicolumn{2}{|c|}{ Instructions } & \multirow[b]{2}{*}{$\begin{array}{c}\text { F value } \\
(1,60)\end{array}$} & \multirow[b]{2}{*}{$P$ level } & \multirow[b]{2}{*}{ ES } \\
\hline & $\begin{array}{l}\text { Honest } \\
\text { M (SE) } \\
95 \% \text { CI }\end{array}$ & $\begin{array}{c}\text { Malinger } \\
\text { M (SE) } \\
95 \% \text { CI }\end{array}$ & & & \\
\hline Cognitive & $\begin{array}{c}120.02(2.48) \\
115.06,124.98\end{array}$ & $\begin{array}{l}93.43(2.86) \\
87.73,99.17\end{array}$ & 65.88 & $<.001$ & .52 \\
\hline Emotional & $\begin{array}{c}8.00(0.48) \\
7.04,8.95\end{array}$ & $\begin{array}{l}10.46(0.54) \\
9.39,11.54\end{array}$ & 28.34 & $<.001$ & .32 \\
\hline \multirow[t]{2}{*}{ Scores } & \multicolumn{2}{|c|}{ Gender } & & & \\
\hline & $\begin{array}{c}\text { Females } \\
\text { M (SE) } \\
95 \% \mathrm{CI}\end{array}$ & $\begin{array}{c}\text { Males } \\
\text { M (SE) } \\
95 \% \text { CI }\end{array}$ & $\begin{array}{c}\text { F value } \\
(1,60)\end{array}$ & $P$ level & ES \\
\hline Cognitive & $\begin{array}{l}105.47(2.90) \\
99.68,111.26\end{array}$ & $\begin{array}{c}108.00(3.09) \\
101.82,114.18\end{array}$ & 0.36 & ns & .01 \\
\hline Emotional & $\begin{array}{l}9.28(0.62) \\
8.05,10.52\end{array}$ & $\begin{array}{l}9.17(0.66) \\
7.86,10.49\end{array}$ & 0.10 & ns & .00 \\
\hline
\end{tabular}

ES: Eta-squared effect size.

participation in the experiment, they were required to complete a debriefing form indicating their knowledge of the purpose of the study, the manipulation involved, the data collected, and the task they were to perform. Students who refused to participate and those who did not complete the debriefing form were not included in the sample.

Second, the younger sample of students signed assent forms and their parents and the high school administrator(s) signed informed consent forms. In addition, for this sample, the test was administered in 50-minute sessions to groups of 12 to 15 students during a homeroom period. Finally, in both the college and high school samples, participants were instructed to draw each human figure for the entire five-minute interval. The resulting 636 figures were scored for emotional disturbance and cognitive ability as described in Experiment 1. Scoring was conducted by judges who were not blind to the conditions (Bruening et al., 1997), but had completed the training reliably, as described in Experiment 1.

\section{Results}

A preliminary MANOVA was used to determine if there were differences in scores for the figures of man, woman, and self. There were no significant differences as a function of figure in the emotional disturbance or cognitive scores in the honest and malinger conditions, Wilks' Lambda $=0.98$, $F(4,1258)=2.04, n s$, eta squared $=.01$. Therefore, further analyses used the total scores, composed of the combined scores of man, woman, and self, for the emotional disturbance and cognitive scoring systems.

Table 2 presents the means of the total cognitive scores and total emotional scores for the honest and malinger instructional conditions. A repeated measures ANOVA was conducted on the cognitive scores, with condition (honest vs. malinger) as a within-subjects variable and gender and age group (high school vs. college) as between-subjects factors.
As shown in Table 2, there was a significant main effect for condition, reflecting higher cognitive ability scores in the honest condition than in the malinger condition. There were no gender differences (see Table 2) and no age group differences in total cognitive scores between high school $(M=$ 133.26, $S E=3.17,95 \% \mathrm{CI}=126.98$ to 139.54$)$ and college students $(M=134.62, S E=2.41,95 \% \mathrm{CI}=129.83$ to $139.41), F(1,102)=.12, n s$, eta-squared $=.00$. Also, the interaction between condition and gender was not significant.

However, there was a significant interaction between age group and condition $F(1,102)=10.71, p<.001$, eta-squared $=.10$. To investigate this interaction, change scores were calculated for cognitive scores; the change scores were obtained for each participant from the honest condition to the malinger condition. An independent samples $t$-test found greater changes in cognitive scores for high school students $(M=22.42, S E=3.25)$ than for college students $(M=10.39$, $S E=2.00), t(104)=3.33, p<.001$. Fig. (1) illustrates the cognitive scores as a function of condition, gender, and age group.

Similarly, a repeated measures ANOVA was conducted on the emotional disturbance scores, with condition as a within-subjects variable and gender and age group as between-subjects factors. As shown in Table 2, there was a significant main effect for condition, with higher emotional disturbance scores in the malinger condition than in the honest condition. There were no gender and no age group differences in total emotional disturbance scores, and the interaction between condition and gender was not significant.

However, the main effect of instructions on emotional disturbance scores was qualified by significant interactions between condition and gender, $F(1,102)=4.72, p<.05$, etasquared $=.04$, and between condition and age group, $F(1$, 
$102)=5.91, p<.05$, eta-squared $=.06$. No other results were significant. To investigate the interactions, change scores were calculated for emotional scores; the change scores were obtained for each participant from the honest condition to the malinger condition. Independent samples $t$-tests found greater changes in emotional scores for males $(M=5.58, S E$ $=.80)$ than females $(M=3.57, S E=.75)$, and greater change scores for high school $(M=5.87, S E=1.15)$ than for college students $(M=3.48, S E=.54)$. Fig. (2) illustrates the emotional disturbance scores as a function of condition, gender, and age group.

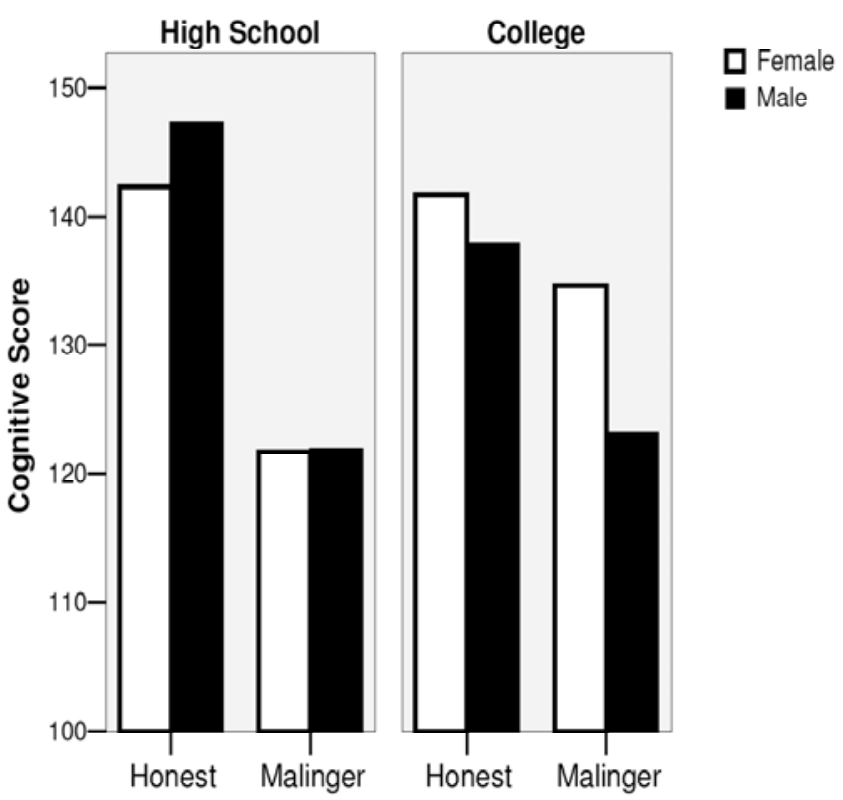

Fig. (1). Cognitive scores on the Draw-A-Person test as a function of condition, gender, and age group. Higher scores indicate greater cognitive abilities.

It is possible that the change in emotional disturbance scores from the honest condition to the malinger condition is attributable to the concurrent change in cognitive scores. ${ }^{1}$ To examine this possibility, a repeated measures analysis of covariance was conducted on the emotional disturbance scores, using the change in cognitive scores as a covariate, with condition as a within-subjects factor and gender and age group as between-subjects factors. There was a main effect of condition, $F(1,101)=13.55, p<.001$, eta-squared $=.12$, with higher scores in the malinger condition $(M=19.34, S E$ $=.70,95 \% \mathrm{CI}=17.95$ to 20.74$)$ than in the honest condition $(M=14.68, S E=.57,95 \% \mathrm{CI}=13.55$ to 15.80$)$. In addition, there were significant differences in scores between high school $(M=21.95, S E=.96,95 \% \mathrm{CI}=20.05$ to 23.85$)$ and college students $(M=12.07, S D=.72,95 \% \mathrm{CI}=10.65$ to 13.49), $F(1,101)=65.42, p<.001$, eta-squared $=.39$. No other results were significant. Therefore, the increases in emotional disturbance scores from the honest condition to the malinger condition are not attributable to the corresponding change in cognitive scores.

\footnotetext{
${ }^{1}$ Thank you to Kang Lee for pointing out this possibility.
}

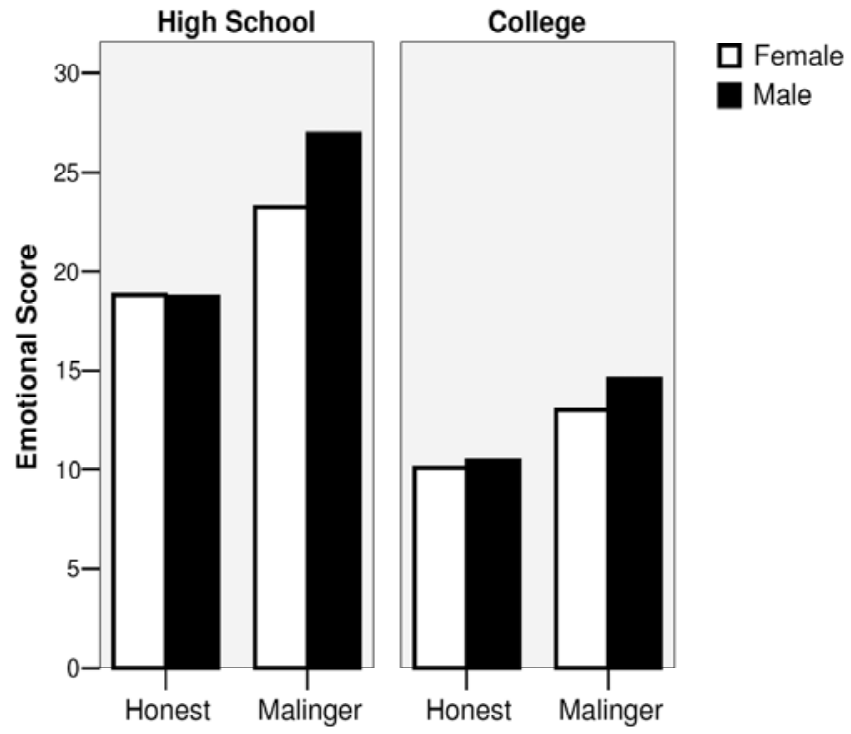

Fig. (2). Emotional disturbance scores on the Draw-A-Person test as a function of condition, gender, and age group. Higher scores indicate greater emotional disturbance.

\section{Discussion}

As in Experiment 1, participants demonstrated the ability to malinger distress on the DAP task, but they concurrently decreased their cognitive scores on the task in doing so. This suggests a potential role for objective cognitive scores in the assessment of malingering on DAP tests. Such malingering is clearly within the capacity of even high school students, yet these younger participants were especially likely to feign with lowered cognitive scores, reinforcing this tendency as a possible signal to malingering attempts.

\section{GENERAL DISCUSSION}

The current research contributes to the literature on deception and malingering in the context of a projective psychological evaluation. Specifically, the goals of the research were to examine whether participants would be able to feign emotional distress on human figure drawings and whether the use of two objective scoring systems might eventually assist in determining when participants were malingering distress on DAP projective tests. Results from both high school and college student samples suggest that adolescents and young adults are capable of feigning distress on the task. However, their technique, as detected by the Naglieri scoring system, seems to involve drawing figures that are more primitive than they are capable of drawing. Of course, the tactics chosen by the participants in this study may differ from those used by individuals to feign trauma in a forensic setting. Hence, future research might investigate the usefulness of the cognitive ability scale in detecting deceptive responding.

Three methods used to interpret drawings are typically identified (Lally, 2001). First, clinicians and researchers use their global qualitative impression to arrive at conclusions about the artist's personality characteristics and level of pathology. This widely used method involves little or no formal scoring, and the interpreter relies on their phenomenological experience of the drawing, affective or visceral reac- 
Table 2. Draw-A-Person Scores by Instructions and Gender, Experiment 2

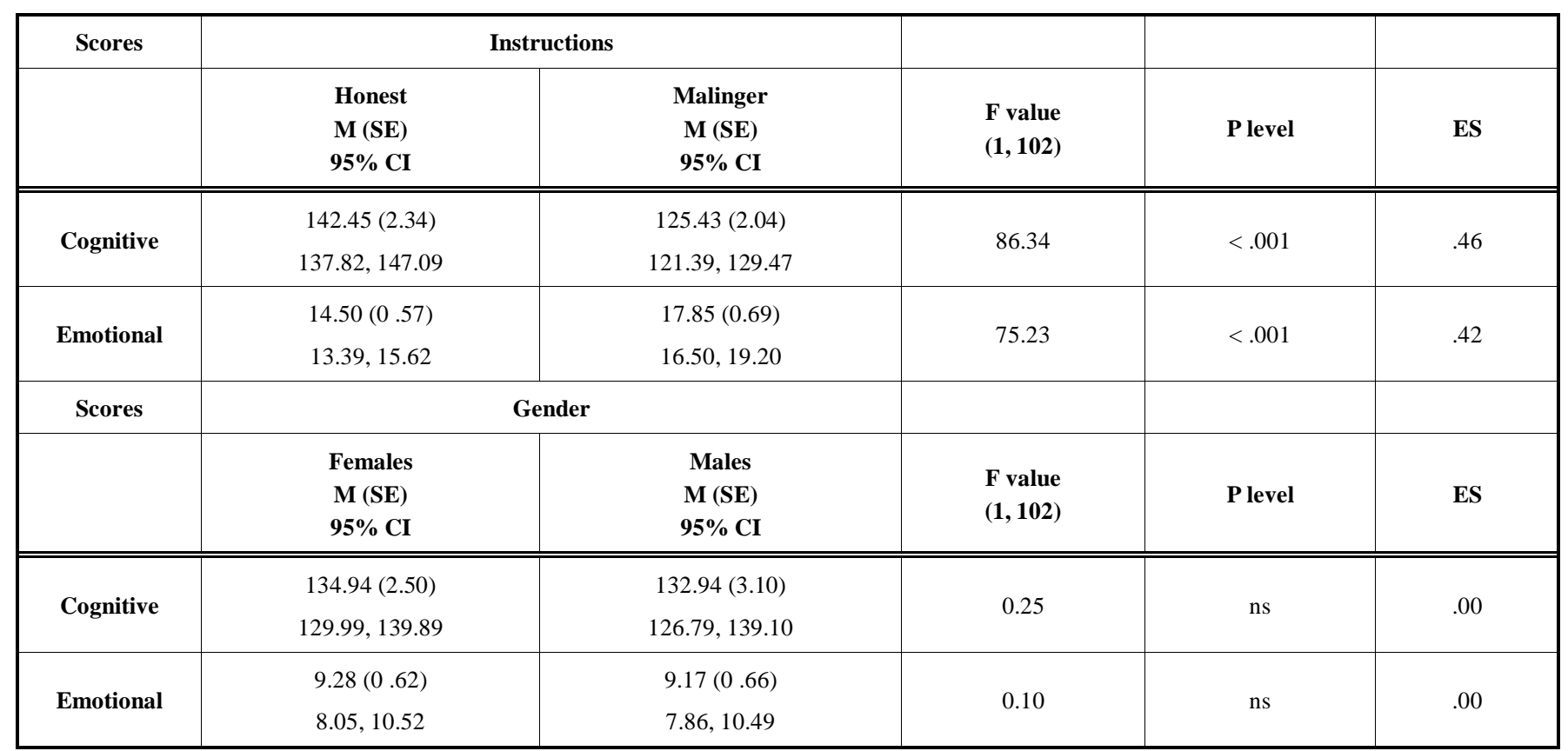

ES: Eta-squared effect size.

tions to it, and loosely reigned impressions and associations. Other methods link single signs with specific aspects of personality or specific diagnoses, and the third type of method focuses on the frequency of indicators of pathology in a drawing. A comparison is made between the number of such items in a drawing and normative information about the expected frequency and conclusions are then drawn about the presence of maladjustment (e.g., Koppitz, 1968; DAP:SPED, Naglieri et al., 1991; Van Hutton, 1994). Given the variability of method of use, and lack of sufficient validation of the various methods, it has been argued that the use of such tests in forensic settings is premature (Lally, 2001). Such a determination rests on both legal standards for evidentiary admissibility and psychometric criteria. Currently, controversy exists over the use of draw-a-person tests in general. For example, Lilienfeld, Wood, and Garb (2000) indicated that there are currently no reliable scoring systems for DAP, with the exception of Naglieri's system, which showed some promise. Indeed, use, interpretation, and acceptance of DAP tests is not uniform.

The current research raises additional questions about the use of the DAP task, which was vulnerable to malingering by adolescents and young adults. This is consistent with previous findings that, even before adolescence, individuals become accomplished (and frequent) liars and that their skills include the ability to malinger (Amini, Talwar, \& Crossman, 2010; Carmody \& Crossman, 2005; Crossman \& Lewis, 2006). Given that adolescents and young adults are the group most likely to suffer MVAs, the current results could have important implications for understanding their potential for feigning reactions to MVAs.

However, the findings also suggest that DAP malingerers (at least at these ages) might have a "tell" - their cognitive ability scores. Although this study lacked an independent measure of participants' cognitive ability, such a measure might be a promising avenue for future investigation of means for detecting malingering (Salekin, Kubak, \& Lee, 2008). Instances where the estimates of cognitive ability based on the drawing scores are much lower than those on an independent cognitive assessment might raise red flags for an interviewer. This might be a particularly useful comparison, as some research suggests DAP tests are more accurate at determining the artist's developmental level or cognitive ability than at detecting emotional disturbance (ter Laak, de Goede, Aleva, \& van Rijswijk, 2005). This is not to suggest that the DAP should be used alone for assessments. Because feigned cognitive impairments are a source of concern as well, especially when litigation is involved, use of objective cognitive tests with components to assess malingering seems appropriate (Salekin et al., 2008). Clinicians have available and make use of a variety of such tools and skills for this task, but by thoroughly examining the validity and reliability of each, researchers can help to enhance the overall usefulness of available measures.

Malingering in the current research was not a high stakes exercise for the participants or for the raters and the consequences of failure were not severe. Nevertheless, individuals managed to significantly influence their scores for imagined distress in an artificial, laboratory setting. In addition, raters were not blind to condition in the current studies. Yet, previous research has shown that raters' knowledge of abuse status of patients did not affect the application of the objective DAP:SPED scoring system (Bruening et al., 1997). Hence, it seems reasonable to suggest that raters' knowledge of honest and malinger conditions for the drawings in this study are unlikely to have influenced application of the objective scoring systems. Instead, the unanticipated divergence of cognitive and emotional disturbance scores suggests that the trend reflected a strategy, consciously or not, relied upon by malingerers in accomplishing their task. 


\section{CONCLUSIONS}

Overall, this analysis makes clear the need for great caution in the use and application of DAP projective testing. In the limited pursuit of rapport-building with clients, it might have some clear advantages over various other clinical techniques. The DAP task might allow patients to express themselves non-verbally in relatively unthreatening ways (Riethmiller \& Handler, 1997). Alternatively, its use late in an interview to jog additional memory, as suggested by Aldridge et al. (2004), could be beneficial. However, consistent with data on relatively conservative rates of administration (Archer, Buffington-Vollum, Stredny \& Handel, 2006), the use of drawing as a diagnostic or forensic tool is currently questionable, particularly given sparse, but clear, information regarding the potential for malingering on such a measure.

\section{ACKNOWLEDGEMENT}

Portions of the research were presented the $8^{\text {th }}$ Annual National Forensics Conference, Las Vegas, NV, October 2000, and at the symposium Cutting-edge developments in children and youths' deception and adults' ability to detect $i$, K. Nysse-Carris (Chair), held at the meeting of the American Psychology-Law Society, Scottsdale, AZ, March 2004.

\section{REFERENCES}

Ackerman, M. J., \& Schoendorf, K. (1992). Ackerman-Schoendorf Scales for Parent Evaluation of Custody (ASPECT). Los Angeles: Western Psychological Services.

American Psychiatric Association. (1994). Diagnostic and statistical manual of mental disorders. (4 ${ }^{\text {th }}$ Ed.) Washington, DC: American Psychiatric Association.

Aldridge, J., Lamb, M. E., Sternberg, K. J., Orbach, Y., Esplin, P. W., \& Bowler, L. (2004). Using a human figure drawing to elicit information from alleged victims of child sexual abuse. Journal of Consulting and Clinical Psychology, 72, 304-316.

Amini, N., Talwar, V., \& Crossman, A. M. (2010, August). Early deception in toddlers. Poster presented at the annual meeting of the American Psychological Association, San Diego, CA.

Archer, R. P., Buffington-Vollum, J. K., Stredny, R. V., \& Handel, R. W. (2006). A survey of psychological test use patterns among forensic psychologists. Journal of Personality Assessment, 87(1), 84-94.

Berry, D. T. R. (1995). Detecting distortion in forensic evaluations with the MMPI-2. In Y. S. Ben-Porath, J. R. Graham, G. C. N. Hall, R. D. Hirschman, \& M. S. Zaragoza (Eds.), Forensic applications of the MMPI-2 (pp. 82-102). Thousand Oaks, CA: Sage.

Blanchard, E. B., \& Hickling, E. J. (1997). After the crash. Washington, DC: American Psychological Association.

Bricklin, B. (1984). Bricklin Perceptual Scales. Furlong, PA: Village.

Bruck, M., Melnyk, L., \& Ceci, S. J. (2000). Draw it again Sam: The effect of drawing on children's suggestibility and source monitoring ability. Journal of Experimental Child Psychology, 77, 169-196.

Bruening, C. C., Wagner, W. G., \& Johnson, J. T. (1997). Impact of rater knowledge on sexually abused and nonabused girls' scores on the Draw-A-Person: Screening Procedure for Emotional Disturbance (DAP:SPED). Journal of Personality Assessment, 68(3), 665-677.

Burgess, A. W., \& Hartman, C. R. (1993). Children's drawings. Child Abuse \& Neglect, 17, 161-168.

Camara, W. J., Nathan, J. S., \& Puente, A. E. (2000). Psychological test usage: Implications in professional psychology. Professional Psychology: Research and Practice, 31, 141-154.

Carmody, D. P., \& Crossman, A. M. (2005). Youth deception: Malingering traumatic stress. Journal of Forensic Psychiatry and Psychology, 16(3), 477-493.

Crossman, A. M., \& Lewis, M. (2006). Adults' ability to detect children's lying. Behavioral Sciences and the Law, 24, 703-715.

DePaulo, B. M., Lindsay, J. J., Malone, B. E., Muhlenbruck, L., Charlton, K., \& Cooper, H. (2003). Cues to deception. Psychological Bulletin, $129,74-112$.
Dykens, E. (1996). The Draw-A-Person task in persons with mental retardation: What does it measure? Research in Developmental Disabilities, 17, 1-13.

Faust, D., Hart, K., \& Guilmette, T. J. (1988). Pediatric malingering: The capacity of children to fake believable deficits on neuropsychological testing. Journal of Consulting and Clinical Psychology, 56, 578-582.

Faust, D., Hart, K., Guilmette, T. J., \& Arkes, H. R. (1988). Neuropsychologists' capacity to detect adolescent malingerers. Professional Psychology: Research and Practice, 19, 508-515.

Guriel, J., Yanez, T., Fremouw, W., Shreve-Neiger, A., Ware, L., Filcheck, H., \& Farr, C. (2004). Impact of coaching on malingered posttraumatic stress symptoms on the M-FAST and the TSI. Journal of Forensic Psychology Practice, 4(2), 37-56.

Handler, L. (1984). Anxiety as measured by the Draw-A-Person test: A response to Sims, Dana, and Bolton. Journal of Personality Assessment, $48(1), 82-84$

Heilbrun, K. (1992). The role of psychological testing in forensic assessment. Law \& Human Behavior, 16, 257-272.

Knox, D., Zusman, M. E., McGinty, K., \& Gescheidler, J. (2001). Deception of parents during adolescence. Adolescence, 36(143), 611-614.

Koppitz, E. M. (1968). Psychological evaluation of children's human figure drawing. New York: Grune \& Stratton.

Kropp, P. R., \& Rogers, R. (1993). Understanding malingering: Motivation, method, and detection. In M. Lewis \& C. Saarni (Eds.), Lying and deception in everyday life (pp. 201-216). New York: Guilford Press.

Lally, S. J. (2001). Should human figure drawings be admitted into court? Journal of Personality Assessment, 76(1), 135-149.

Lev-Wiesel, R., \& Hershkovitz, D. (2000). Detecting violent aggressive behavior among male prisoners through the Machover Draw-A-Person test. Arts in Psychotherapy, 27(3), 171-177.

Lilienfeld, S. O., Wood, J. S., \& Garb, H. N. (2000). The scientific status of projective techniques. Psychology in the Public Interest, 1(2), 27-66.

Matto, H. C. (2002). Investigating the validity of the Draw-A-Person: Screening Procedure for Emotional Disturbance: A measurement validation study with high-risk youth. Psychological Assessment, 14, 221-225.

McCann, J. T. (1998). Malingering and deception in adolescents: assessing credibility in clinical and forensic settings. Washington, D. C.: American Psychological Association.

Naglieri, J. A. (1988). Draw-a-Person: A quantitative scoring system. San Antonio, TX: Psychological Corporation.

Naglieri, J. A., McNeish, T. J., \& Bardos, A. N. (1991). Draw-a-Person: Screening procedure for emotional disturbance. Austin, TX: Pro-ed.

National Highway Traffic Safety Administration (2001). Traffic safety facts 2001: Young drivers. Washington, DC: National Center for Statistics and Analysis of the National Highway Traffic Safety Administration. US Department of Transportation publication HS-809-483.

Ochoa, S. H., Riccio, C., Jimenez, S., de Alba, R. G., \& Sines, M. (2004). Psychological assessment of English language learners and/or bilingual students: An investigation of school psychologists' current practices. Journal of Psychoeducational Assessment 22(3), 185-208.

Peterson, L. W., Hardin, M., \& Nitsch, M. J. (1995). The use of children's drawings in the evaluation and treatment of child sexual, emotional, and physical abuse. Archives of Family Medicine 4(5), 445-452.

Quinn, K. (1988). Children and deception. In R. Rogers (Ed.), Clinical assessment of malingering and deception. New York: Guilford Press.

Resnick, P. J. (1997). Malingering of posttraumatic disorders. In R. Rogers (Ed.) Clinical assessment of malinger and deception ( $2^{\text {nd }}$ ed., pp. 130152). New York: Guilford.

Riethmiller, R. J., \& Handler, L. (1997). Problematic methods and unwarranted conclusions in DAP research: Suggestions for improved research procedures. Journal of Personality Assessment 69(3), 459-475.

Rogers, R., Hinds, J. D., \& Sewell, K. W. (1996). Feigning psychopathology among adolescent offenders: Validation of the SIRS, MMPIA, and SIMS. Journal of Personality Assessment 67, 244-257.

Rogers, R. (Ed.). (2008). Clinical assessment of malingering and deception $\left(3^{\text {rd }}\right.$ ed.). New York: Guilford.

Salekin, R. T., Kubak, F. A., \& Lee, Z. (2008). Deception in children and adolescents. In R. Rogers (Ed.), Clinical assessment of malingering and deception ( ${ }^{\text {rd }}$ ed., pp. 343-364). New York: Guilford.

Schretlen, D. J. (1997). Dissimulation on the Rorschach and other projective measures. In R. Rogers (Ed.), Clinical assessment of malingering and deception ( $2^{\text {nd }}$ ed., pp. 208-222). New York: Guilford.

Sims, J., Dana, R. H., \& Bolton, B. (1983). The validity of the Draw-APerson test as an anxiety measure. Journal of Personality Assessment 47(3), 250-257. 
Smith, D., \& Dumont, F. (1995). A cautionary study: Unwarranted interpretations of the Draw-A-Person test. Professional Psychology: Research and Practice 26, 298-303.

Strange, D., Garry, M., \& Sutherland, R. (2003). Drawing out children's false memories. Applied Cognitive Psychology 17, 607-619.

Talwar, V., \& Lee, K. (2002a). Development of lying to conceal a transgression: Children's control of expressive behaviour during verbal deception. International Journal of Behavioral Development 26, 436444.

Talwar, V., \& Lee, K. (2002b). Emergence of white lie telling in children between 3 and 7 years of age. Merrill-Palmer Quarterly 48, 160-181.

ter Laak, J., de Goede, M., Aleva, A., \& van Rijswijk, P. (2005). The DrawA-Person test: An indicator of children's cognitive and socioemotional adaptation? The Journal of Genetic Psychology 166(1), 77-93.
Tharinger, D. J., \& Stark, K. (1990). A qualitative versus quantitative approach to evaluating the Draw-A-Person and Kinetic Family Drawing: A study of mood and anxiety-disordered children. Psychological Assessment 2, 365-375.

Williams, T. O., Jr., Fall, A.-M., Eaves, R. C., \& Woods-Groves, S. (2006). The reliability of scores for the Draw-A-Person intellectual ability test for children, adolescents, and adults. Journal of Psychoeducational Assessment 24(2), 137-144.

Wilson, A. E., Smith, M. D., \& Ross, H. S. (2003). The nature and effects of young children's lies. Social Development 12, 21-45.

Wilson, D., \& Ratekin, C. (1990). An introduction to using children's drawings as an assessment tool. The Nurse Practitioner 15(3), 23-24, 27, 30-35.

(C) Carmody and Crossman; Licensee Bentham Open.

This is an open access article licensed under the terms of the Creative Commons Attribution Non-Commercial License (http://creativecommons.org/licenses/by-nc/3.0/) which permits unrestricted, non-commercial use, distribution and reproduction in any medium, provided the work is properly cited. 